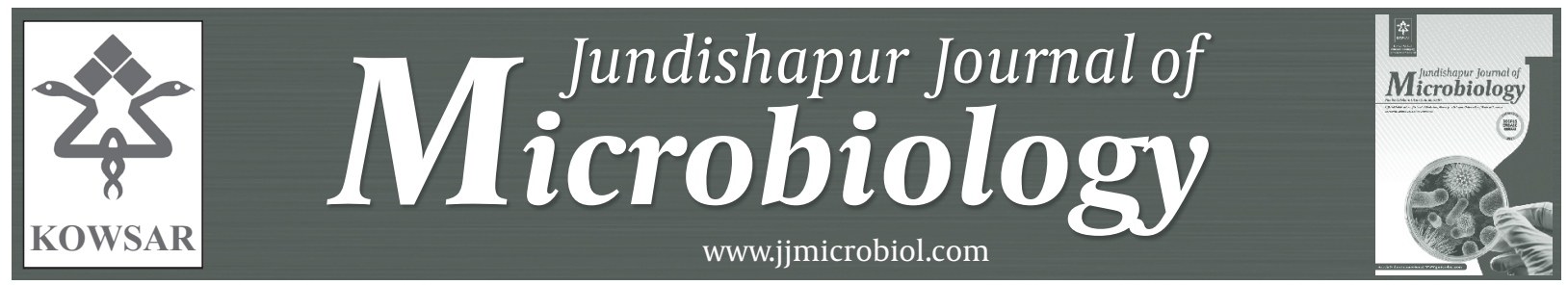

\title{
The Impact of Two Purified Forms of Bordetella Pertussis CyaA on Oxidative Burst
}

\author{
Seyed Abdolmajid Khosravani ${ }^{1}$, John Coote ${ }^{2}$, Roger Parton ${ }^{2}$, Seyed Mohammad Ali Man- \\ sourian ${ }^{1}$, Seyed Abdolrahim Rezaee ${ }^{3,{ }^{*}}$
}

${ }^{1}$ Department of Microbiology, Yasuj University of Medical Sciences, Yasuj, IR Iran

2 Department of Microbiology, University of Glasgow, Glasgow, UK

${ }^{3}$ Immunology Research Centre, Medical School, Mashhad University of Medical Sciences, Mashhad, IR Iran

*Corresponding author: Seyed Abdolrahim Rezaee , Department of Immunovirology, Mashhad University of Medical Sciences, Mashhad, IR Iran. Tel: +989155148304, E-mail:a_rezaee@hotmail.com.

\begin{abstract}
A B S T R A C T
Background: Adenylate cyclase toxin (CyaA) is an important virulence factor of Bordetella pertussis, the causative agent of whooping cough, and a potential component of acellular pertussis vaccine.

Objectives: In the present study the impact of invasive CyaA on oxidative activities of phagocytes was compared with the other form of this molecule to investigate the activity of different parts of molecules on leukocytes.

Materials and Methods: The work involved the production of two purified forms of CyaA with different enzymic and invasive properties. They were: the native enzymatically-active, invasive toxin (CyaA), an invasive derivative lacking AC enzymic activity (Cya $A^{*}$ ). Different concentrations of CyaA and CyaA* were used to investigate dose-dependent effects of the toxins on oxidative burst in U937 human monoblastic cells, J774.2 mouse macrophage-like cells and fresh human granulocyte cells by Burst Test assay.

Results: Significant effects were observed with $0.2 \mu \mathrm{g}$ protein $/ \mathrm{mL}$ of CyaA. For instance, there was almost complete (80\%) inhibition of phagocytosis by $\mathbf{7 7 4 . 2}$ cells and 70\% inhibition of phagocotosis by human granulocyte cells. The results showed that production of the oxidative burst was significantly impaired by increasing concentrations of CyaA compared to cells treated with PBS. However, there was no significant effect with CyaA* on either cells.

Conclusions: The results of the study showed that both enzymatic and invasive functions were required for the oxidative burst effects of adenylate cyclase toxin in leukocytes.
\end{abstract}

Keywords: B. Pertussis; Adenylate cyclase toxin; Oxidative Burst

Copyright @ 2013, Ahvaz Jundishapur University of Medical Sciences; Published by Kowsar Corp.

-Article type: Research Article; Received: 22 Apr 2012; Revised: 20 Jun 2012; Accepted: 08 Aug 2012; Epub: 01 Jun 2013; Ppub: Jun 2013 Implication for health policy/practice/research/medical education:

With regard to the several properties of this toxin, we wanted to determine the effetcs of it on different mamalian cells in a way that we could use it as a vaccine against B. Pertussis. It is worth to know that V. Pertussis was previuosly used in combination with diphtheria and Tetani, but the present study aimed to use this toxine alone for preparing the mentioned vaccine.

Please cite this paper as:

Khosravani SA, Coote J, Parton R, Mansourian SMA, Rezaee SA. The Impact of Two Purified Forms of Bordetella Pertussis CyaA on Oxidative Burst. Jundishapur J Microbiol. 2013;6(4):e5227. DOI:10.5812/jjm.5227.

Copyright (C) 2013, Ahvaz Jundishapur University of Medical Sciences; Published by Kowsar Corp.

This is an Open Access article distributed under the terms of the Creative Commons Attribution License (http://creativecommons.org/licenses/by/3.0), which permits unrestricted use, distribution, and reproduction in any medium, provided the original work is properly cited. 


\section{Background}

Bordetella pertussis is a human pathogen, Gram-negative bacteria causative agent of whooping cough. It secretes several virulence factors including adhesins which consist filamentous hemagglutinin (FHA), pertactin (PRN) and toxins such as tracheal cytotoxin, pertussis toxin (PT), and adenylate cyclase-hemolysin (AC-Hly), allowing it to multiply and colonize the human respiratory epithelium (1). Among them, adenylate cyclase toxin (CyaA) is a major virulence factor of B. Pertussis and anti-CyaA antibodies are present in sera from convalescent patients and patients vaccinated with WCVs $(2,3)$. CyaA is a 177 kDa protein endowed with adenylate cyclase (AC) activity and with the ability to invade and intoxicate mammalian cells (4).

Upon entry into the cell, the N-terminal AC enzymic moiety is activated by host calmodulin to produce supraphysiological levels of cyclic AMP (cAMP). In immune effector cells, it impairs their phagocytic and bactericidal capabilities and induces apoptosis, features which are assumed to assist survival of the bacteria in the initial stages of respiratory tract colonisation (5). At high concentrations, CyaA forms pores or channels which make the toxin cytolytic (4). Anti-CyaA antibodies have been shown to enhance phagocytosis of B. Pertussis through neutralisation of CyaA which, normally inhibits phagocytosis by neutrophil polymorphonuclear leukocytes ( 6 , 7). An immune response to this toxin might therefore be useful to prevent colonisation of the host by B. Pertussis. Immunisation with CyaA, purified from B. Pertussis or in recombinant form from Escherichia coli, protected mice against intranasal challenge with virulent $B$. Pertussis (8-10). In addition, co-administration of CyaA or CyaA*, a derivative lacking AC enzymic activity, with an ACV indicated the enhancement of the protective effects of an ACV in mice (11).

\section{Objectives}

The aim of the work reported here was to formulate CyaA by a method that is applicable to large-scale manufacture but which would still allow retention of the enzyme activity and immunogenicity of the protein.

\section{Materials and Methods}

\subsection{Preparation of Recombinant CyaA From E. coli}

Twenty $\mathrm{mL}$ of an overnight culture of E. coli BL21/DE3 containing the relevant plasmids were diluted into 500 $\mathrm{mL}$ of LB containing appropriate antibiotics, incubated at $37 \mathrm{C}$ with shaking at $200 \mathrm{rpm}$ until an OD600nm of between 0.4-0.45 was obtained ( $\sim 3 \mathrm{~h}$ ). Isopropyl-1-thio--Dgalactoside (IPTG) was added to a final concentration of $1 \mathrm{mM}$ and shaking continued at 37C for $3 \mathrm{~h}$. Finally, cells were harvested at 10,000 xg for $25 \mathrm{~min}$ and the supernatant discarded. Cells pellets could be stored at -20C if necessary.

\subsection{Expression and Purification of CyaA}

E. coli BL21/DE3 ( F - ompT $\mathrm{rB}-\mathrm{mB}-$ ) was used as the host strain for production of CyaA. The source of plasmids used in this study ( pGW44 and pGW54) was described previously $(12,13)$. Co-expression of pGW44 with pGW54 generates fully active acylated, invasive CyaA , pGW44-188, pGW54 generates Non-active AC/ invasive $\left(\mathrm{CyaA}^{*}\right)$. The recombinant proteins were purified as described previously with the following modifications; the CyaA inclusion bodies were washed twice with $1 \%(\mathrm{w} / \mathrm{v})$ $\mathrm{N}$-octyl -d glucopyranoside (Sigma, Sweden in $20 \mathrm{mM}$ histidine buffer ( $\mathrm{pH} 6.0$ ), twice with $2 \mathrm{M}$ urea in $20 \mathrm{mM}$ histidine buffer ( $\mathrm{pH}$ 6.0) and once with pyrogen-free water before solubilisation in $8 \mathrm{M}$ urea, $20 \mathrm{mM}$ histidine buffer (pH 6.0). The solubilised crude CyaA was purified by QSepharose, Germany Amersham) and phenyl-Sepharose chromatography ( Figures 1 and 2).

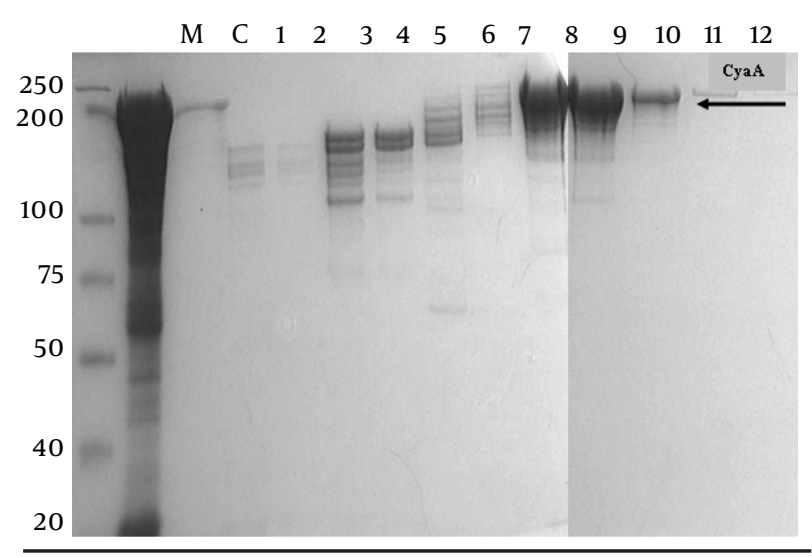

Figure 1. SDS-PAGE of Crude CyaA after Q Sepharose Purification

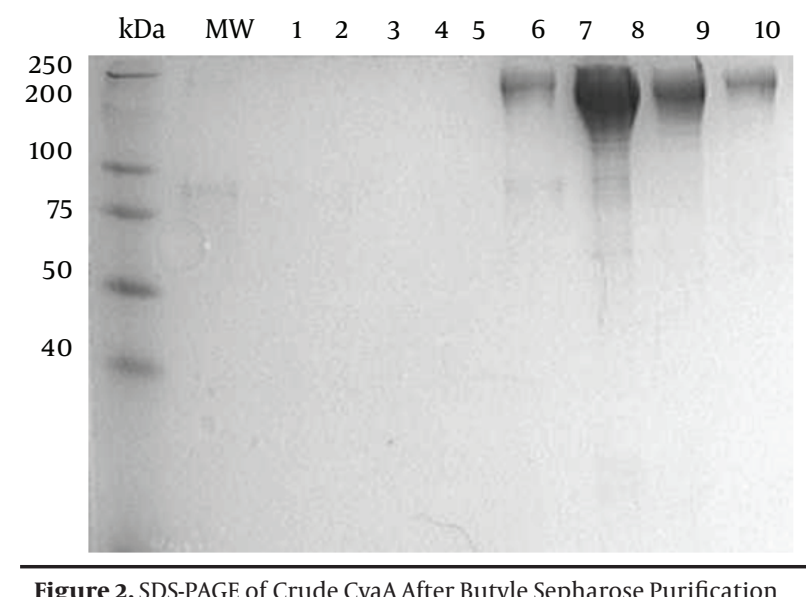

\subsection{Oxidative Burst Procedure}

The oxidative burst component of the phagocytic process was measured in leukocytes using the commercial flow cytometric-based BurstTest kit (OPREGEN Pharma; BD Biosciences, U.S.A) according to the manufacturer's instruction for E.coli bioparticles. The BurstTest assay 
relied on unlabelled IgG opsonized E.coli bacteria as the particulate stimulus and dihydrorhodamine (DHR) 123 as a fluorogenic substrate of oxidative activity. Briefly, both heparinised whole blood, and J774.2 mouse macrophages and U937 human monocytes were incubated (120 minutes, $37^{\circ} \mathrm{C}, 5 \% \mathrm{CO} 2$ ) with either recombinant CyaA or

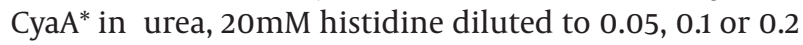
g protein/mL or with $\mathrm{PBS}$, then incubated for another 15 minutes at $37^{\circ} \mathrm{C}$ in $5 \% \mathrm{CO} 2$ with opsonized E. coli cells (6 cells per leukocyte).

A sample without stimulus served as negative background control. DHR 123 was then added and the cells incubated ( 10 minutes, $37^{\circ} \mathrm{C}, 5 \% \mathrm{CO} 2$ ). The reaction was stopped by the addition of lysing buffer, which partially fixes leukocytes and lyses erythrocytes in case of whole blood. After washing steps ( $250 \mathrm{x} \mathrm{g}, 5 \mathrm{~min}, 4^{\mathrm{O}} \mathrm{C}$ ) erythrocytes were removed by hypotonic lysis. Finally, to exclude aggregation artefacts of bacteria or platelets, a DNA staining solution was added immediately prior to flow cytometric analysis. Cells were analysed by flow cytometry (FACS.Calibur, BD Biosciences, U.S.A) and 5000 granulocyte or diploid cell events acquired to obtain the percentage and number of cells ingesting bioparticles, as well as their mean fluorescence intensity (enzymatic activity) using Cellquest Pro software (BD Biosciences, U.S.A).

Nucleated cells were discriminated by setting in the red fluorescence channel (DNA staining FL2), on those events which had the DNA content of a human diploid cell (to exclude bacteria aggregates). The nucleated events were then discriminated; in to lymphocytes, monocytes and polymorphonuclears by combined measurements of the forward angle light scatter (FSC) and side angle light scatter (SSC). The granulocyte cluster or U937 or J774 in different tests was then gated in the analysis program in the scatter diagram (FSC vs. SSC) and its green fluorescence histogram (FL1) was analysed. The SSC vs. FL-1 diagram also was set to make sure that the appropriate cell population data were collected.
Flow cytometry assays for the measurement of the oxidative burst were based on the conversion of a nonfluorescent molecule to the fluorescent form under the influence of intracellular reactive oxygen intermediates. This conversion reflected the amount of oxidative burst induced by various stimuli. The substrate used was dihydrorhodamin-123 (DHR-123), which entered the cells as a freely permeable dye and was converted to rhodamine 123. It was used as an indicator of oxidative burst and was found to be more sensitive than other substrates.

The cells (human granolocytes, J774.2 and U937) were treated with CyaA and CyaA* (0.05, 0.1 and 0.2 g protein/ $\mathrm{mL}$ final concentration) for two hours and then incubated with opsonised E. coli for $15 \mathrm{~min}$. In addition, some of the cells were incubated with PBS instead of CyaA, as controls. Cells were washed and then read by flow cytometry at a wave length of $488 \mathrm{~nm}$.

The statistically significant results obtained with CyaA were substantiated by the flow cytometric histograms (Images 2 and 4 in Figure 3).

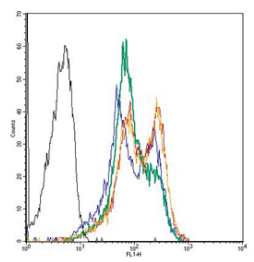

1)
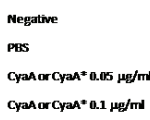

CyaA orCyaA* $0.2 \mu / m$ m

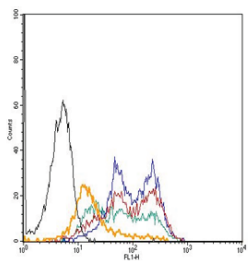

2)

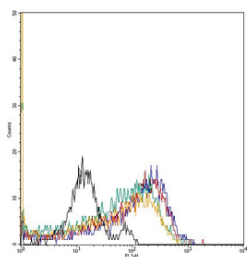

3)

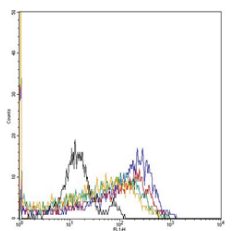

4)
Figure 3. The Effect of CyaA and CyaA* on Inhibition of Oxidative Burst by E. coli Stimulation on J774.2 Cells and Human Granulocyte Cells Using Burst Test.

\section{Results}

Table 1. Inhibition of Oxidative Burst Activity of Human Granolocytes, J774.2 and U937 Cells by CyaA Preparations

\begin{tabular}{|c|c|c|c|c|}
\hline Toxin conc, $\mathrm{g} / \mathrm{mL}$ & $\begin{array}{l}\text { Inhibition of Oxida- } \\
\text { tive Burst in J774.2 } \\
\text { Cells (Mouse Macro- } \\
\text { phages) } \%\end{array}$ & $\begin{array}{l}\text { Inhibition of Oxida- } \\
\text { tive Burst in Granulo- } \\
\text { cytes (Human Periph- } \\
\text { eral Blood), \% }\end{array}$ & $\begin{array}{l}\text { Inhibition of Oxida- } \\
\text { tive Burst in U937 Cells } \\
\text { (Human Monocytes) } \\
\text { (Without PMA), \% }\end{array}$ & $\begin{array}{l}\text { Inhibition of Oxida- } \\
\text { tive Burst in U937 Cells } \\
\text { (Human Monocytes) } \\
\text { (With PMA), \% }\end{array}$ \\
\hline СуаA $^{\mathrm{a}}(0.05)$ & 18 & 35 & 0 & 15 \\
\hline $\operatorname{CyaA}^{\mathrm{a}}(\mathbf{0 . 1})$ & 38 & 55 & 0 & 40 \\
\hline $\operatorname{CyaA}^{\mathrm{a}}(\mathbf{0 . 2})$ & 80 & 70 & 0 & 53 \\
\hline $\mathrm{CyaA}^{* \mathrm{~b}}(0.05)$ & 0 & 0 & 0 & 0 \\
\hline $\mathrm{CyaA}^{* \mathrm{~b}}(\mathbf{0 . 1})$ & 0 & 0 & 0 & 0 \\
\hline $\mathrm{CyaA}^{* \mathrm{~b}}(\mathbf{0 . 2})$ & 0 & 21 & 0 & 0 \\
\hline PBS & 0 & 0 & 0 & 0 \\
\hline
\end{tabular}

${ }^{\mathrm{a}} \mathrm{CyaA}=$ This toxin has both invasive and enzymatic activity

${ }^{\mathrm{b}} \mathrm{CyaA}^{*}=$ This toxin has invasive property, but no enzymatic activity 
Images 1 and 3 showed that CyaA* had little effect on J774.2 and or granulocytes only at the highest concentration. Similar experiments were carried out with undifferentiated and differentiated U937 human monoblast treated with CyaA at $0.1 \mathrm{~g} / \mathrm{mL}$. As Table 1 shows, only differentiated cells were affected by CyaA.

These tests are a flow cytometeric assay which relays on unlabelled IgG opsonized E.coli bacteria as the particulate stimulus and dihydrorhodamine (DHR) 123 as a fluorogenic substrate of oxidative activity.

\section{Discussion}

The first line of defence against microbial infection was provided by neutrophils. Upon phagocytosis of bacteria, a respiratory burst occurred; initially reducing oxygen to form superoxide, with secondary formation of $\mathrm{H}_{2} \mathrm{O} 2, \mathrm{OH}^{-}$ and other oxygen-derived molecules that participated in bacterial killing (14). An early report showed that culture medium and bacterial extract from B. Pertussis, containing adenylate cyclase of high specific activity, were able to inhibit the chemiluminescence (CL) response of human alveolar macrophages and neutrophils to zymosan (15).

Others have reported the role of CyaA in the inhibition of this response. CyaA toxin produces high levels of intracellular cAMP in human monocytes and inhibits the oxidative response to a variety of particulate or soluble stimuli (16). Other researchers demonstrated that B. Pertussis can survive intracellularly within various leukocyte cell types, including human macrophages and polymorphonuclear cells $(17,18)$. It is possible that the inhibition of oxidative burst in these cells would benefit from the intracellular survival of the bacteria which may be an important evasive strategy for B. Pertussis.

The results of oxidative burst experiments in the current study suggested that CyaA inhibits the oxidative burst of J774.2 macrophage-like cells and human granulocytes as it induced a decrease in mean fluorescent intensity (MFI) as measured by flow cytometry. Although the concentration of CyaA used in the assay caused appreciable cell killing of J774.2 cells, as determined by the MTT assay, it should be emphasised that the effect of CyaA on oxidative burst was measured only in viable cells, by the flow cytometric method, here in contrast, CyaA* did not appear to inhibit the oxidative burst when it was compared with CyaA at the same concentrations. The results indicated that the AC enzymic activity of CyaA toxin was necessary for the inhibition of oxidative burst in these cells. This result is in line with Steed et al. (18) who indicated that CyaA inhibited respiratory burst activity in human PMNL.

A similar experiment, preformed on U937 human monocytes in the presence and absence of PMA, showed that CyaA inhibited the oxidative burst by approximately $15 \%$, $40 \%$ and 53\% when tested at $0.05,0.1$ and $0.2 \mu \mathrm{g} / \mathrm{mL}$ final concentrations on PMA-activated monocytes respectivly, but were ineffective on non-differentiated cells. Thus, PMA could stimulate the immature cells to differentiate, which CyaA then affected. These data suggested that the activity of CyaA on these cells were best seen when they differentiated, possibly to express high level of receptor for CyaA.

\section{Acknowledgements}

The authors are grateful to Yasuj University of Medical sciences of Iran for financial support. Authors wish to thank Dr. Barbara Orr for her useful help during the study.

\section{Financial Disclosure}

There was not any conflict of interest for this study.

\section{Funding Support}

None declared.

\section{Authors' Contribution}

None declared.

\section{References}

1. Mattoo S, Foreman-Wykert AK, Cotter PA, Miller JF. Mechanisms of Bordetella pathogenesis. Front Biosci. 2001;6:E168-86.

2. Cherry JD, Xing DX, Newland P, Patel K, Heininger U, Corbel MJ. Determination of serum antibody to Bordetella pertussis adenylate cyclase toxin in vaccinated and unvaccinated children and in children and adults with pertussis. Clin Infect Dis. 2004;38(4):502-7.

3. Farfel Z, Konen S, Wiertz E, Klapmuts R, Addy PA, Hanski E. Antibodies to Bordetella pertussis adenylate cyclase are produced in man during pertussis infection and after vaccination. J Med Microbiol.1990;32(3):173-7.

4. El Azami El Idrissi M, Ladant D, Leclerc C. The adenylate cyclase of Bordetella pertussis: a vector to target antigen presenting cells. Toxicon. 2002;40(12):1661-5.

5. Gueirard P, Druilhe A, Pretolani M, Guiso N. Role of adenylate cyclase-hemolysin in alveolar macrophage apoptosis during Bordetella pertussis infection in vivo. Infect Immun. 1998;66(4):171825.

6. Mobberley-Schuman PS, Connelly B, Weiss AA. Phagocytosis of Bordetella pertussis incubated with convalescent serum. J Infect Dis. 2003;187(10):1646-53.

7. Weingart CL, Mobberley-Schuman PS, Hewlett EL, Gray MC, Weiss AA. Neutralizing antibodies to adenylate cyclase toxin promote phagocytosis of Bordetella pertussis by human neutrophils. In fect Immun. 2000;68(12):7152-5.

8. Betsou F, Sebo P, Guiso N. CyaC-mediated activation is important not only for toxic but also for protective activities of Bordetella pertussis adenylate cyclase-hemolysin. Infect Immun. 1993;61(9):3583-9.

9. Guiso N, Szatanik M, Rocancourt M. Protective activity of Bordetella adenylate cyclase-hemolysin against bacterial colonization. Microb Pathog. 1991;11(6):423-31.

10. Hormozi K, Parton R, Coote J. Adjuvant and protective properties of native and recombinant Bordetella pertussis adenylate cyclase toxin preparations in mice. FEMS Immunol Med Microbiol. 1999;23(4):273-82.

11. Cheung GY, Xing D, Prior S, Corbel MJ, Parton R, Coote JG. Effect of different forms of adenylate cyclase toxin of Bordetella pertussis on protection afforded by an acellular pertussis vaccine in a murine model. Infect Immun. 2006;74(12):6797-805.

12. Khosravani A, Parker MC, Parton R, Coote J. Formulation of the adenylate cyclase toxin of Bordetella pertussis as protein-coated 
microcrystals. Vaccine. 2007;25(22):4361-7.

13. Westrop GD, Hormozi EK, Da Costa NA, Parton R, Coote JG. Bordetella pertussis adenylate cyclase toxin: proCyaA and CyaC proteins synthesised separately in Escherichia coli produce active toxin in vitro. Gene. 1996;180(1-2):91-9.

14. Uhlinger DJ, Tyagi SR, Inge KL, Lambeth JD. The respiratory burst oxidase of human neutrophils. Guanine nucleotides and arachidonate regulate the assembly of a multicomponent complex in a semirecombinant cell-free system. JBiol Chem. 1993;268(12):862431.

15. Confer DL, Eaton JW. Phagocyte impotence caused by an invasive bacterial adenylate cyclase. Science. 1982-217(4563):948-50.

16. Pearson RD, Symes P, Conboy M, Weiss AA, Hewlett EL. Inhibition of monocyte oxidative responses by Bordetella pertussis adenylate cyclase toxin.J Immunol. 1987;139(8):2749-54.

17. Saukkonen K, Cabellos C, Burroughs M, Prasad S, Tuomanen E. Integrin-mediated localization of Bordetella pertussis within macrophages: role in pulmonary colonization. J Exp Med. 1991;173(5):1143-9.

18. Steed LisaLovett. Host-parasite interactions between Bordetella pertussis and human polymorphonuclear leukocytes. 1991. 